\title{
ETNOGEOMORFOLOGIA SERTANEJA - O CONHECIMENTO TRADICIONAL DO PRODUTOR RURAL NORDESTINO SOBRE O RELEVO E SEUS PROCESSOS NA SUB-BACIA DO RIO SALGADO/CE ${ }^{1}$
}

\author{
ANTÔNIO CARLOS DE BARROS CORREA ${ }^{2}$ \\ Universidade Federal de Pernambuco \\ MÔNICA DOS SANTOS MARÇAL ${ }^{3}$ \\ Universidade Federal do Rio de Janeiro \\ SIMONE CARDOSO RIBEIRO 4 \\ Universidade Regional do Cariri
}

Resumo: As áreas semiáridas, devido a suas características morfoesculturadoras, apresentam um equilíbrio extremamente frágil diante da dinâmica ambiental. Nas áreas de produção agropecuária, o manejo agrícola dos solos tem sido um dos principais responsáveis pela aceleração dos processos morfodinâmicos. Este trabalho objetiva identificar como os produtores familiares sertanejos da sub-bacia do rio Salgado entendem os processos geomorfológicos, como usam este conhecimento para o manejo do ambiente onde vivem e se, e como, utilizam destes saberes para algum tipo de classificação da

\footnotetext{
${ }^{1}$ Retirado da tese de doutorado da primeira autora, orientado pelos demais autores, intitulada "ETNOGEOMORFOLOGIA SERTANEJA: proposta metodológica para a classificação das paisagens da sub-bacia do rio Salgado/CE", defendida em 2012 na PPGG/UFRJ.

${ }^{2}$ Professor adjunto do Departamento de Ciências Geográficas da UFPE; pós-doutor em Geografia. Contato: dbiase2001@terra.com.br.

${ }^{3}$ Professora adjunta do Departamento de Geografia da UFRJ; doutora em Geografia. Contato: monicamarcal@ufrj.br.

${ }^{4}$ Professora adjunta do Departamento de Geociências da Universidade Regional do Cariri - URCA; doutora em Geografia. Contato: simonecribeiro@ oi.com.br.
} 
paisagem. Para isso, desenvolveu-se uma metodologia no âmbito da Etnogeomorfologia voltada para nortear o desvendamento, a compreensão e a sistematização, com base científica, de todo um conjunto de teorias e práticas relativas ao ambiente oriundas de experimentação empírica por culturas tradicionais; que contribua para orientar a inserção e o desenvolvimento de pesquisas junto às comunidades rurais sertanejas e dar subsídios à gestão territorial sob a ótica do desenvolvimento local, partindo do pressuposto de que as informações que as pessoas possuem sobre seu ambiente e a maneira pela qual categorizam tais informações influenciarão seu comportamento em relação a ele. Visitaram-se comunidades rurais em que entrevistas roteirizadas forneceram dados para a análise desta compreensão etnogeomorfológica. $\mathrm{O}$ resultado obtido condiz com a hipótese levantada, de acordo com a qual existe um conhecimento etnogeomorfológico do produtor rural do semiárido nordestino que vem sendo passado através das gerações, desde o povoamento da região, de forma vernacular. Tais saberes estão intrinsecamente relacionados às práticas agropastoris e produzem uma classificação/denominação dos fatos/processos geomórficos bastante peculiar.

Palavras-chave: Etnoconhecimento geomorfológico; Sertão nordestino; Ceará.

\section{ETHNOGEOMORPHOLOGY OF SEMI-ARID LANDS - TRADITIONAL KNOWLEDGE OF RURAL NORTHEASTERN PRODUCER ON THE RELIEF AND ITS PROCESSES IN SUB-BASIN RIVER SALGADO / CE}

Abstract: The semi-arid areas, due to its characteristics morfoesculturadoras, have an extremely fragile balance in the face of environmental dynamics. In the areas of agricultural production, agricultural soil management has been a major contributor to the acceleration of morphodynamic processes. This study aims to identify how family hinterland farmers sub-basin of the Salgado river, understand the geomorphological processes, how they use this knowledge to manage the environment in which they live and whether and how they use this knowledge to some kind of landscape classification. For this, we developed a methodology under Ethnogeomorphology, facing guide the unveiling, understanding, and systematic, scientifically based around a set of theories and practices related to the environment, derived from empirical experimentation by traditional cultures, and to help guide the development and insertion of surveys to rural hinterland of traditional culture, to give subsidies for land management from the perspective of local development, assuming that the information that people have about their environment, and the way which they categorize this information will influence their behavior towards him. Were visited rural communities where scripted interviews, provided data for the analysis of this understanding etnogeomorfologica. The result is consistent with the hypothesis, in which there is a knowledge etnogeomorfológico the farmer's semiarid northeast that has been handed down through the generations since the settlement of the region, so vernacular. These knowledge 
are intrinsically related to agropastoral practices and produces a rank / designation of facts / geomorphic processes rather peculiar.

Keywords: Geomorphological ethnoknowledge; Northeastern hinterland; Ceará.

\section{1 - Introdução}

As áreas semiáridas, devido a suas características morfoesculturadoras - quais sejam, alto poder erosivo das chuvas, solos pouco coesos e com pouca espessura e baixa proteção da cobertura vegetal esparsa - apresentam um equilíbrio extremamente frágil diante da dinâmica ambiental. Quando a vegetação natural é retirada os processos morfogênicos deflagrados pelos elementos do clima - em especial pela erosão - tendem a se acelerar.

Associado ao fato do Nordeste brasileiro ser a área semiárida mais habitada do mundo e de que suas populações se aglomeram cada vez mais nos núcleos urbanos devido às dificuldades de se manterem no meio rural, a compreensão dos mecanismos que agem na dinâmica geomorfológica destas regiões é de suma importância para o seu ordenamento territorial.

Diante dessa constatação, a compreensão do conhecimento tradicional sobre o meio ambiente vem sendo vista como essencial ao entendimento das realidades ambientais locais das pessoas - neste caso, especialmente a dos agricultores e pecuaristas -, sendo crucial para o potencial sucesso ou fracasso de qualquer tipo de desenvolvimento baseado nestas atividades pois pode ser considerada como ponto de partida para uma parceria mais efetiva entre produtores rurais e técnicos agrícolas.

A identificação, a apreensão e a sistematização dos conhecimentos vernaculares que as populações tradicionais do sertão nordestino desenvolveram durante todo seu histórico de convívio com a terra, tanto no tocante à habitação quanto à produção de sua subsistência, sobre os processos morfoesculturadores da superfície terrestre - como as diferenças entre as formas de relevo, suas características e relações com usos e manejos - podem e devem ser consideradas quando em uma intervenção dos órgãos estatais em seus planejamentos e através de políticas públicas voltadas aos meios e populações rurais, pois

(...) a identificação das potencialidades do meio natural é um tipo de conhecimento mais do que obrigatório para uma discussão aprofundada das sérias questões sociais, econômicas e demográficas envolvidas na estruturação interna dos espaços semiáridos (AB'SABER, 1974, p. 32). 
A partir dessas reflexões passou-se a vislumbrar a sub-bacia do rio Salgado, localizada no sudeste do Estado do Ceará (ver Figura 01), como um espaço geográfico propício ao desenvolvimento de uma pesquisa voltada à relação entre os saberes tradicionais do homem do campo com sua produção familiar de subsistência sobre os processos geomorfológicos e suas formas correlatas e os usos e manejo dos solos feitos por eles a fim de subsidiar planos de gestão ambiental e territorial levados a termo nestas áreas.

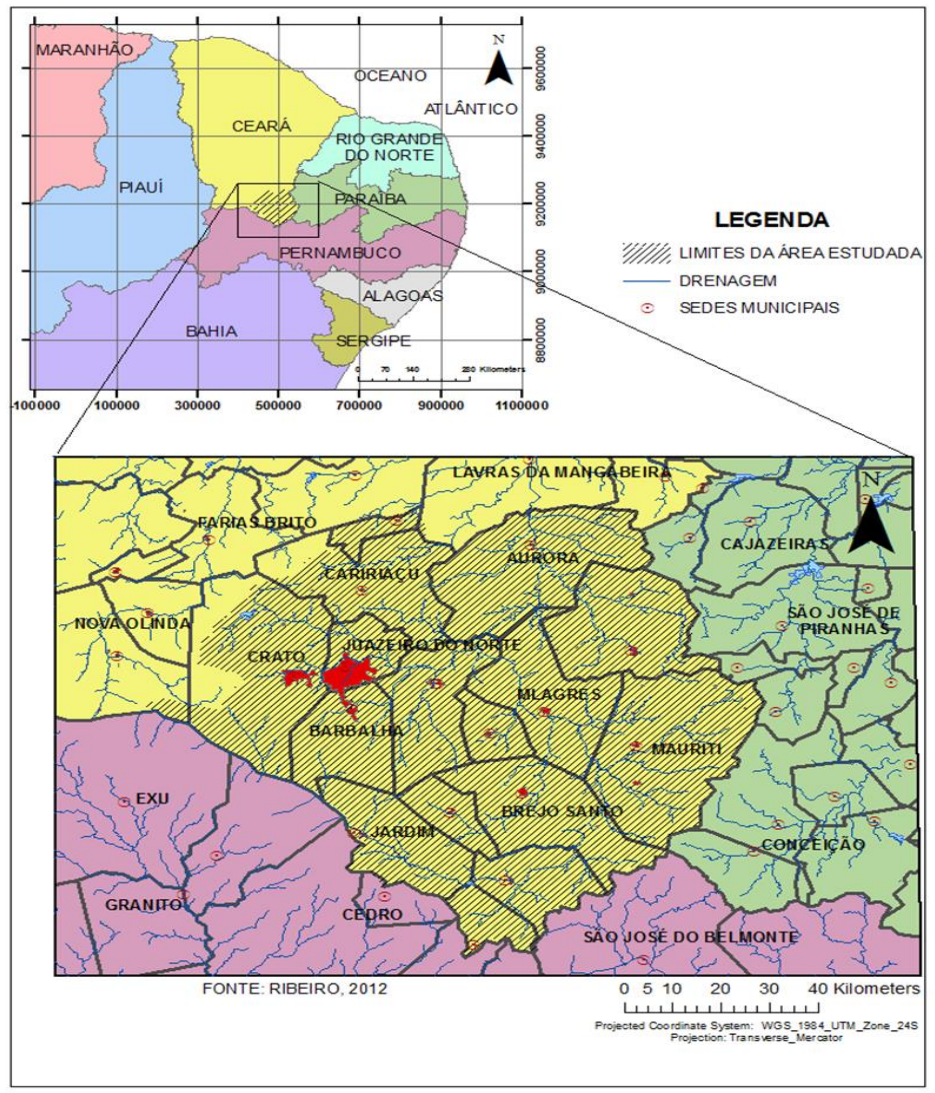

Figura 1: Localização da área da sub-bacia do rio Salgado na Mesorregião Sul cearense. 
Sendo a sub-bacia do Salgado composta por duas áreas geoambientalmente distintas e representativas da maior parte do sertão nordestino - a saber, a) uma sedimentar, com grande aporte de recursos hídricos, solos mais férteis e uma densa aglomeração urbana (CRAJUBAR - Crato-Juazeiro do Norte-Barbalha), pertencendo ao chamado Cariri cearense; e b) outra cristalina, seca, com baixíssimos índices de produção -, pode ser utilizada para realizar estudos de identificação dos usos e manejos do solo a partir dos saberes tradicionais das comunidades locais sobre o relevo e seus processos elaboradores.

\section{2 - Pressupostos Teóricos}

A análise científica do conhecimento tradicional tem sido uma referência importante para reavaliar os paradigmas dos modelos coloniais e agrícolas de desenvolvimento e servir de base ao desenho de modelos alternativos.

Como afirma Escobar (2005), há uma crescente produção de pesquisas e trabalhos que demonstram que comunidades locais empregam a natureza de formas impressionantemente diferentes das formas modernas dominantes: eles designam e, portanto, utilizam os ambientes naturais de maneiras muito particulares, através de uma quantidade de práticas (significativamente diferentes) de pensar, relacionar-se, construir e experimentar o biológico e o natural.

O conhecimento advindo de culturas que mantêm com a natureza relações diferentes daquelas baseadas nas convicções modernas da ciência vem sendo resgatado a partir da constatação de que qualquer planejamento ou gestão ambiental necessita levar em consideração os modelos de natureza baseados no lugar, assim como as práticas e racionalidades culturais, ecológicas e econômicas que os acompanham. Como salienta Escobar,

O fato é que o lugar - como experiência de uma localidade específica com algum grau de enraizamento, com conexão com a vida diária, mesmo que sua identidade seja construída e nunca fixa - continua sendo importante na vida da maioria das pessoas, talvez para todas (2005).

Assim, há uma ausência do lugar nos trabalhos da ciência moderna, a qual tem sido ignorada pela maioria dos pensadores da filosofia ocidental (CASEY, 1993, apud ESCOBAR, 2005). E o enfraquecimento do conhecimento sobre este lugar (que se relaciona com o local, o trabalho e as 
tradições) frente ao global (igualado ao espaço, ao capital e à história) tem consequências profundas em nossa compreensão da cultura, do conhecimento, da natureza e da economia; pois a experiência de desenvolvimento significa para a maioria das pessoas um rompimento com o lugar - o que no âmbito ecológico está vinculado à invisibilidade dos modelos culturalmente específicos da natureza. (ESCOBAR, 2005).

Estes modelos locais, segundo o autor, evidenciam um arraigamento especial ao território concebido como uma entidade multidimensional que resulta dos muitos tipos de práticas e relações e estabelecem vínculos entre os sistemas simbólicos e culturais e as relações produtivas, que podem ser altamente complexas (ESCOBAR, 2005).

Dentro dessa perspectiva, um dos enfoques que mais tem contribuído para se compreender o conhecimento das populações tradicionais é o da Etnociência (DIEGUES, 1996), uma vez que esta "parte da linguística para estudar o conhecimento das populações humanas sobre os processos naturais, tentando descobrir a lógica subjacente ao conhecimento humano do mundo natural, as taxonomias e classificações totais" (DIEGUES, 1996, p.78).

Toledo (2000, apud ALVES; MARQUES, 2005, p. 323) define etnoecologia como sendo "um enfoque interdisciplinar que estuda as formas pelas quais os grupos humanos veem a natureza, através de um conjunto de conhecimentos e crenças; e como os humanos, a partir de seu imaginário, usam e, ou, manejam os recursos naturais".

Segundo Diegues (1996), a Etnoecologia entende o ambiente como constituído de seres, saberes, relações e cultura e busca resgatar os saberes tradicionais no intuito de relacioná-los aos saberes científicos. Ou seja, ela traz para a discussão acadêmica a ideia de que o manejo e o conhecimento dos ecossistemas significam, em última instância, uma relação de conhecimento e ação entre as populações e seu ambiente. E mais, essas populações adquiriram um conhecimento próprio e, consequentemente, tradicional sobre o ambiente em que vivem.

Este conhecimento, denominado como Conhecimento Ecológico Tradicional, caracteriza-se como um complexo sistema de saberes, compreensões, hábitos e crenças provenientes da experiência de uma população tradicional com o seu ambiente. Como afirma Laraia (2009, p. 45) "O homem é o resultado do meio cultural em que foi socializado. Ele é um herdeiro de um longo processo acumulativo, que reflete o conhecimento e a experiência adquiridos pelas numerosas gerações que o antecederam". 


\section{A Etnogeomorfologia na busca do conhecimento geomorfológico tradicional}

A relação entre evolução das formas de relevo e uso e manejo destas pelas sociedades é intrínseca. De acordo com Boardman (1993), nos últimos 5.000 anos a sensibilidade dos solos à erosão tem mudado, assim como os solos também o têm. Segundo estudos feitos no sudeste da Inglaterra, o loess original da região - com uma história de mais de 5.000 anos de cultivos e erosão intermitentes - encontra-se removido ou com sua espessura bastante diminuída. E como essa remoção da superfície do solo é o primeiro passo para a esculturação do relevo, podemos afirmar que de acordo com o uso e o manejo aos quais os solos são submetidos teremos uma maior ou menor modificação nas formas da paisagem.

Os processos esculturadores do relevo dependem basicamente de quatro fatores: a mineralogia do substrato rochoso, a morfologia estrutural (previamente produzida pelas forças endógenas), a ação do clima e a ação antrópica sobre o terreno. Como estes dois últimos fatores são visíveis e levados a termo na escala histórica de tempo (muitos deles ocorrendo de forma praticamente instantânea aos olhos do observador), as comunidades tradicionais vêm convivendo e buscando compreendê-los ao longo de sua trajetória de uso e manejo das áreas, em especial aquelas destinadas ao cultivo e à criação.

Partindo desta premissa, a Etnogeomorfologia pode ser definida como uma ciência híbrida que estuda o conhecimento de uma comunidade acerca dos processos geomorfológicos, levando em consideração os saberes sobre a natureza e os valores da cultura e da tradição locais enquanto a base antropológica da utilização das formas de relevo por dada cultura. Assim, são necessários conhecimentos de várias naturezas - como o geomorfológico, o geográfico, o pedológico e etnopedológico, o ecológico e etnoecológico e o antropológico -, voltando-se a etnogeomorfologia principalmente à gestão e ao planejamento do uso do espaço (ver Figura 2). 


\section{GEOMORFOLOGLA}

Processos e formas correl atas,

distribuição e taxonomia

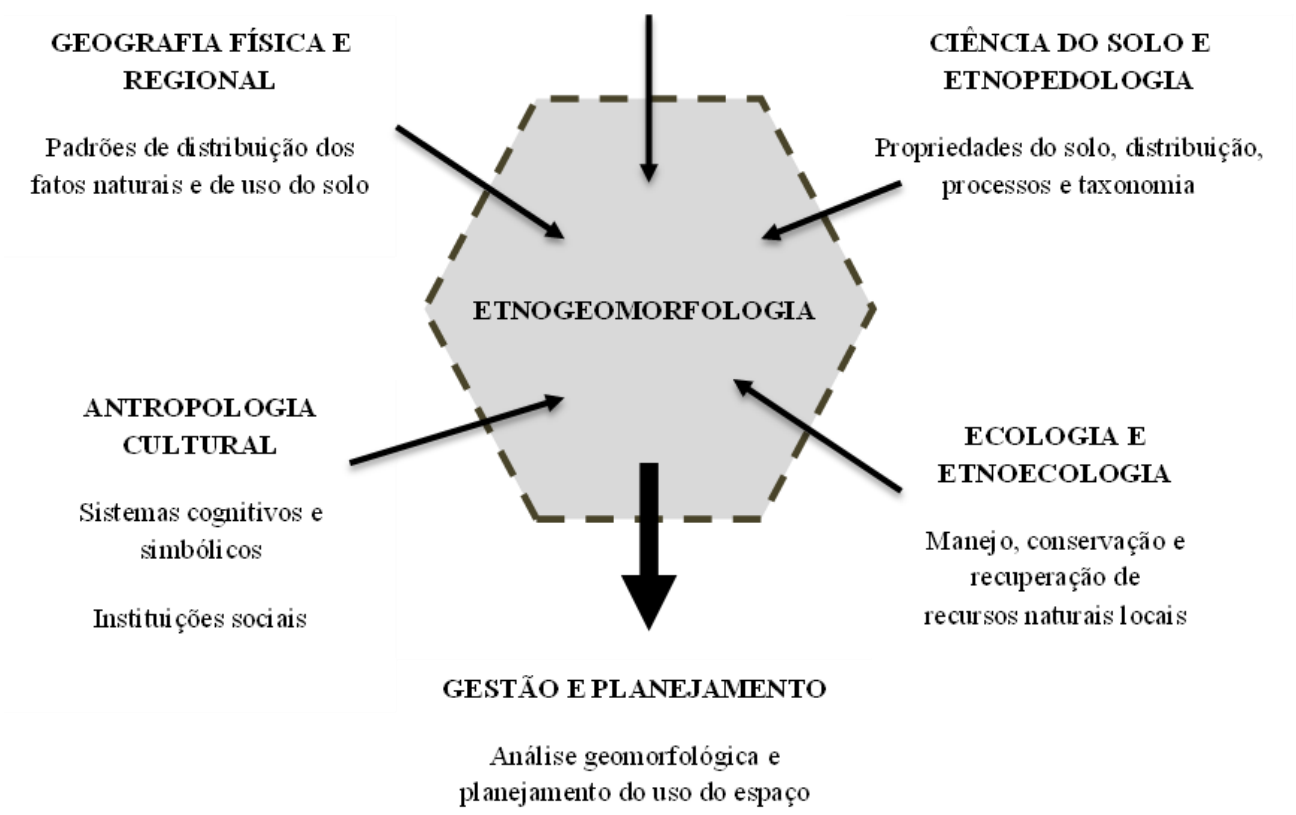

Figura 2: Etnogeomorfologia - ciência híbrida que visa a melhoria do planejamento e da gestão do uso do espaço.

Fonte: RIBEIRO, 2012.

Nessa perspectiva a análise da percepção camponesa sobre esta dinâmica do seu ambiente de vivência e, principalmente, de seu locus produtivo - o solo e as formas de relevo que o influenciam - se faz imprescindível para uma melhor adequabilidade das ações de desenvolvimento socioambiental viabilizadas a partir de políticas públicas de ordenamento territorial. 


\section{3 - Metodologia}

Para chegarmos à compreensão de como e com que eficácia os atores sociais (produtores rurais) transformam a paisagem morfológica através de suas ações produtivas, se fez necessário sabermos como essa paisagem evolui de forma natural de acordo com as leis físicas, químicas e biológicas que regem a morfoesculturação do relevo; assim como se estes agentes de transformação identificam e compreendem tais processos naturais e as influências de seus atos produtivos sobre os mesmos.

Dessa forma, buscou-se criar um método que combinasse as três vertentes dos estudos da paisagem: a) uma voltada para a visão integrativa de seus componentes, em especial o Geossistema e sua relação com o Território e a Paisagem no chamado GTP de Bertrand (2009) e a Ecodinâmica de Tricart (1977) e sua releitura feita por Bólos (1981), a partir da qual foram realizadas as análises sobre os processos morfoesculturadores; b) uma baseada na concepção de Geografia Cultural de Sauer (2007), relacionada às diferentes ações impressas nas formas atuais da paisagem pelas sociedades que nela habitam de acordo com suas histórias e culturas (MATHEWSON; SEEMANN, 2008), da qual foi inferido o conjunto de conhecimentos e técnicas tradicionais que os sertanejos têm e praticam sobre seu locus de vida e produção; e c) uma terceira, tendo os estudos perceptivos de Tuan $(1980 ; 1983)$ como baliza mestra, que mostra como essa paisagem é incorporada na dimensão cognitiva de seus atores, ou seja, a maneira pela qual a percepção que os sertanejos têm dos elementos da paisagem - seus processos e formas - vai influenciar decisivamente suas ações sobre esta, modificando-a e moldando-a.

Portanto, para se compreender a visão etnogeomorfológica das comunidades tradicionais rurais sertanejas é imperativo conhecer previamente a realidade local - tanto em relação aos aspectos geoambientais quanto aos sócio-econômico-culturais - e, então, poder interagir com a comunidade. Assim, os procedimentos metodológicos foram divididos em três fases:

$1^{a}$ fase: Elaboração de material básico a fim de reconhecimento prévio do local de estudo, constou de duas etapas:

1 - A partir do levantamento de dados bibliográficos e cartográficos, utilizando-se conceitos oriundos da visão integrativa da paisagem (TRICART, 1977; 1982; BÓLOS, 1981; 1992), produziu-se mapas e sínteses sobre as características geoambientais e de uso e ocupação do solo. 
2 - Baseando-se em trabalhos de cunho etnoecológico, em especial os de Dayrell (1998) e da FUNAI (2004), foi confeccionado um roteiro para as entrevistas que seriam feitas junto aos produtores rurais.

$2^{\mathrm{a}}$ fase: Pesquisa de campo, quando foram feitas visitas voltadas à identificação e delimitação de unidades geomorfológicas mais específicas e dos usos e manejos do solo pelas comunidades locais; assim como entrevistas com os produtores rurais, no intuito de identificar e analisar seus conhecimentos vernaculares sobre o funcionamento do meio ambiente e, em especial, dos processos geomórficos externos - erosão e movimentos gravitacionais de massa.

Durante as entrevistas visitaram-se as áreas produtivas para melhor observação do manejo do solo, assim como para a identificação de cicatrizes de erosões ou movimentos gravitacionais de massa. Foram utilizadas, também, imagens fotográficas de cicatrizes para possível identificação destas como formas presentes em algum ponto da propriedade ou do sítio, que quando reconhecidas, foram feitas tentativas de identificação de causa, consequências e nomenclaturas.

$3^{\mathrm{a}}$ fase: Análise dos dados, quando se fez a identificação dos saberes comuns a todos os produtores rurais entrevistados e buscou-se responder às seguintes questões sobre eles:

1 - Qual sua percepção ambiental geral sobre sua área de produção, ou seja, como eles veem o ambiente onde produzem? Distinguem formas de relevo? Se sim, baseados em que? Como as classificam/denominam? De onde vêm estes conhecimentos?

2 - Compreendem os processos erosivos? Como? Fazem distinção entre estes processos? Baseados em que fazem esta distinção? Fazem alguma classificação? Relacionam tais processos a algum tipo de atividade humana? De onde vêm estes conhecimentos?

3 - Utilizam este etnoconhecimento no uso e manejo dos solos das áreas produtivas (de agricultura ou pecuária)? De que forma? 


\section{4 - Resultados e Discussões}

\section{As formas do relevo}

Apesar de haver diferenças no tocante principalmente às formas de relevo - pois os locais focados no estudo foram escolhidos exatamente buscando essas diferenças na morfologia -, as classificações e nomenclaturas utilizadas pelos entrevistados se mostraram bastante similares.

Em geral, foram identificadas quatro formas de relevo básicas: "serra", "pé-de-serra", "tabuleiros" e "baixios". E em algumas localidades, devido a formas locais de relevo, outras nomenclaturas foram possíveis: como "chapada" e "talhado" nas proximidades da Chapada do Araripe; e "serrotes" e "areias", nas áreas mais pediplanadas.

"Serra" é a denominação dada pela maioria dos entrevistados para os relevos mais altos e declivosos, onde os solos são mais rasos e pedregosos e os principais processos morfoesculturadores são de degradação - erosões e movimentos gravitacionais de massa -, enquanto "baixios" são os terrenos mais baixos da paisagem, planos, com solos mais profundos originados da acumulação de sedimentos trazidos das partes adjacentes mais elevadas.

Entre estes dois extremos são encontrados os "pés-de-serra" e os "tabuleiros", com declividades medianas, verdadeiras superfícies de transporte (e algumas vezes de acumulação, quando a declividade decai). Enquanto os primeiros localizam-se junto às maiores elevações, sendo pedimentos compostos basicamente de colúvios mal selecionados; os segundos constituem-se de colinas rebaixadas pelos processos de pediplanação, apresentando declividades ainda mais baixas e solos mais rasos e menos pedregosos que os primeiros.

Nas áreas mais próximas da Chapada do Araripe, outras formas de relevo foram identificadas: a "chapada" e o "talhado". A "chapada" é o relevo mais elevado de toda a região, sua superfície de cimeira com forma plana e solos profundos, onde os processos morfoesculturadores são mínimos não havendo entalhamento significativo; e o "talhado" representa a escarpa arenítica, com altíssima declividade (próxima a 90 graus), decorrente dos processos evolutivos de recuo das escarpas da referida chapada, e que produz o material que compõe os colúvios dos "pés-de-serra" e dos "baixios". 
Também nas áreas pediplanadas do médio curso da sub-bacia do Salgado, onde a influência e visualização do grande marco topográfico regional - a chapada do Araripe - não é sentida de forma significativa, duas outras formas de relevo foram identificadas: os "serrotes" e as "areias", relacionadas aos processos morfoesculturadores mais severos. Nestas áreas, basicamente esculpidas em rochas cristalinas metamórficas, a pediplanação alcança índices bastante significativos, com desgaste e aplainamento muito desenvolvidos, gerando uma superfície com desníveis muito pequenos.

Nesse ambiente, qualquer elevação identifica um relevo diferenciado. Assim, tanto os "serrotes" quanto as "areias" são colinas - umas mais elevadas, com desníveis maiores, compostas de solos pedregosos ("serrotes") e outras muito rebaixadas e com solos mais arenosos. São, na verdade, representantes de fases do processo de pediplanação, sendo um mais evoluído que o outro (principalmente por diferenciação litológica, em que os "serrotes" são esculpidos em rochas mais resistentes).

Desse modo, podemos fazer uma relativa comparação entre a classificação do relevo feita a partir do conhecimento geomorfológico acadêmico e aquela baseada na etnogeomorfologia sertaneja, oferendo um quadro correlativo entre as duas formas de saber, complementares quando se trabalha com desenvolvimento local (ver Figuras 3 e 4). 


\section{CLASSIFICAÇÃO GEOMORFOLÓGICA}

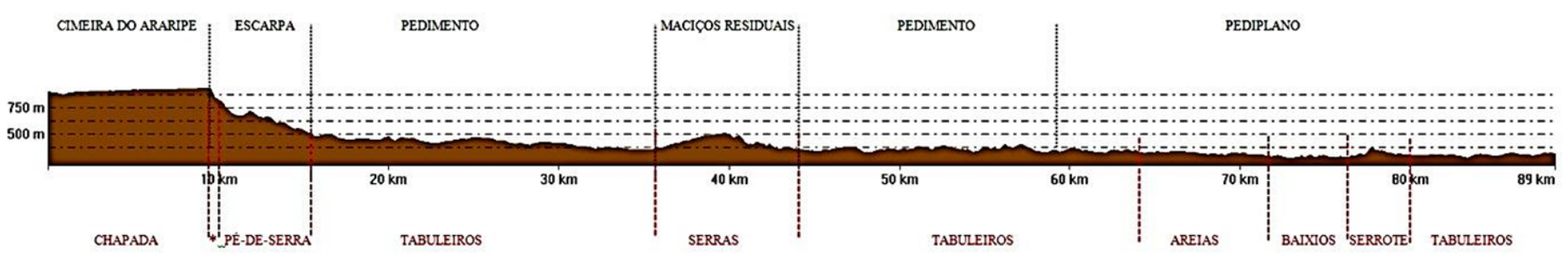

- = TALHADO

\section{CLASSIFICAÇÃO ETNOGEOMORFOLÓGICA}

Figura 3: Comparação entre a Classificação Geomorfológica e a Etnogeomorfológica na sub-bacia do rio Salgado/CE. Fonte: RIBEIRO, 2012. 


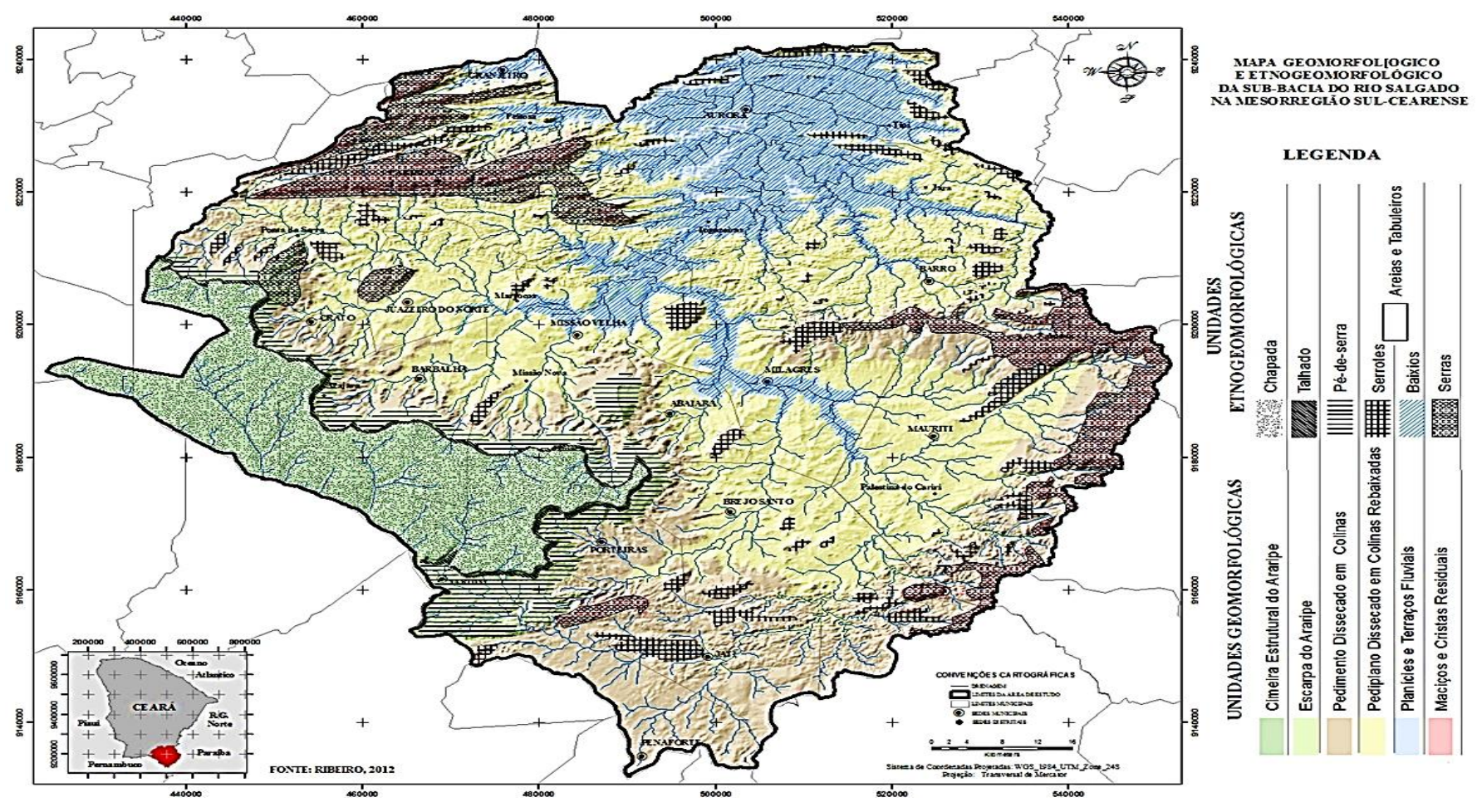

Figura 4: Mapa Geomorfológico e Etnogeomorfológico da Sub-Bacia do Rio Salgado, na Mesorregião Sul-cearense. Fonte: RIBEIRO, 2012. 
Nesse cruzamento de informações podemos observar que as classificações etnogeomorfológicas apresentam correlação bastante alta com a classificação acadêmica quando são levados em consideração os elementos altimetria, declividades e textura topográfica da paisagem, apesar da etnogeomorfologia sertaneja apresentar um maior detalhamento de compartimentos geomórficos. Isto se deve a dois fatores:

1 - À escala de observação dos fatos, uma vez que a classificação acadêmica se fez de forma regional através de imagens SRTM na escala 1:400.000, enquanto a etnogeomorfológica é fruto de conhecimento utilitário cotidiano da paisagem - o que a deixa em uma escala do real. Além disso, nas nomenclaturas utilizadas para designar os compartimentos geomórficos a classificação acadêmica muitas vezes deixa implícita a existência de variabilidade de formas.

2 - À taxonomia etnogeomorfológica que algumas vezes se repete em compartimentações geomórficas acadêmicas diferentes, visto que não leva em consideração a gênese das formas mas sim apenas sua fisionomia e características pedológicas - como no caso dos serrotes e tabuleiros, identificados pelos entrevistados tanto nas áreas de pedimentos quanto nos pediplanos, que apresentam-se como similares na etnogeomorfologia porém na classificação acadêmica são manifestações de etapas diferenciadas do processo de aplainamento geral da região, pelas quais as colinas do pediplano estão em um grau mais avançado de rebaixamento.

\section{Os processos geomórficos}

Dos conceitos desenvolvidos pelos produtores rurais sobre os processos geomórficos externos, existem alguns que se mostraram recorrentes e que são bem compreendidos por todos:

1 - O solo pode ser perdido através de dois processos: a erosão difusa e a erosão concentrada. A erosão difusa, que eles denominam "perda da goma da terra", é relacionada por eles principalmente às grandes quantidades de chuvas ("inverno muito forte"), mas também ao fato dos solos estarem "cansados".

Segundo os produtores rurais, quando não se devolve ao solo o que os cultivos retiram eles vão enfraquecendo e as chuvas fortes retiram a "goma da terra" - ou seja, o que dava união às partículas dos solos (argilas e matéria orgânica) -, assim como a "vitamina da terra" (nutrientes) - o que dá força 
ao plantio - indo, ambas, para os locais mais baixos do terreno ou para os rios e riachos mesmo que isso não seja visível (sem cicatrizes).

A erosão concentrada, que deixa cicatrizes nos terrenos ("solo cortado", "valetas" e "levadas"), também é vista como decorrência das chuvas fortes, porém, relacionada principalmente (mas não somente) ao solo descoberto e ao uso de tratores, uma vez que o arado muito profundo traça os caminhos preferenciais para o escoamento das águas e acaba sendo "cavado" cada vez mais por elas.

2 - Locais mais declivosos são mais propícios para processos de perda de solos - tanto pela erosão quanto por movimentos gravitacionais de massa, uma vez que os desníveis aumentam a força das águas.

3 - Os movimentos gravitacionais de massa ocorrem devido ao encharcamento e, consequente, ao aumento de peso dos solos localizados em áreas de maiores declividades. Segundo os entrevistados, principalmente aqueles dos sítios localizados em áreas próximas de serras ou da chapada do Araripe, quando há uma chuva muito intensa os solos das áreas de "serras" ou do "talhado" (ou seja, com maiores declividades) absorvem muita água, tornando-se mais pesados e "desabando".

4 - Se há perda de solos em um local, há acúmulo em outro: o solo perdido pelos processos erosivos vai se acumular em algum lugar mais baixo - nos "baixios" ou nos leitos dos rios e riachos. Assim, foram identificados locais onde os "baixios cresceram" (acumularam sedimentos e expandiram suas áreas), como também locais onde os "rios ficaram mais rasos" (assorearam).

5 - A fertilidade não é a única característica que deve ser considerada para classificar um solo como bom ou ruim: a "estrutura" (as características físicas) também é importante, uma vez que não adianta um solo ser fértil (ou seja, ter muitos nutrientes disponíveis) se ele apresentar muita pedregosidade ou for muito duro.

Segundo os entrevistados, os solos das "serras" geralmente são férteis mas têm uma "estrutura" muito ruim para trabalhar (rasos e com muitas pedras misturadas), o que faz com que não sejam produtivos. Solos muito encharcados ("embrejados") ou muito duros quando secos (aqueles que contêm argilas do tipo montmorilonitas em sua composição) podem apresentar também produtividades baixas pelas dificuldades a serem trabalhados. Ponderando que os etnoconhecimentos geomórficos
(etnogeomorfologia) destes produtores rurais foram desenvolvidos a partir 
de observações dos processos durante gerações ("empiricismo prático"), podemos considera-los como muito aproximados daqueles acadêmicos, distinguindo-se deles apenas pelas denominações dadas (às formas e processos) e pelo componente eminentemente prático de seus conceitos, uma vez que foram produzidos de forma concomitante às necessidades de melhor compreender o ambiente do qual dependem para a sobrevivência, pois como já afirmou Ab'Saber (2010, p. 557-558),

Os sertanejos têm pleno conhecimento das potencialidades produtivas de cada espaço ou subespaço dos sertões secos. Vinculado a uma cultura de longa maturação, cada grupo humano do Polígono das Secas tem sua própria especialidade no pedaço em que trabalha.

Portanto, para fins de um desenvolvimento pelo qual se procura uma maior articulação entre as potencialidades locais (recursos naturais, recursos humanos, cultura, infraestrutura, etc.) para organizar a produção com vistas às melhorias de vida da população, podemos propor a mesclagem dos conhecimentos acadêmicos e tradicionais no tocante aos saberes etnogeomorfológicos, a fim de estimular as práticas benéficas à produção e ao ambiente; assim como esclarecer - de maneira mais consistente, coerente e dentro da lógica cognitiva dos atores locais - o porquê de algumas formas de manejo do solo serem prejudiciais à manutenção de um ambiente saudável e de uma produção constante.

\section{5 - Considerações Finais}

O conceito de Etnogeomorfologia foi desenvolvido levando em consideração a lógica da Etnociência, ou seja, as relações de conhecimento e ação entre populações tradicionais, seu ambiente e seus recursos - que resultam em correlações entre diversidade biológica e cultural, uma vez que a análise científica do conhecimento tradicional tem sido uma referência importante para reavaliar os paradigmas dos modelos coloniais e agrícolas de desenvolvimento e servir de base ao desenho de novos modelos alternativos.

De forma geral, a etnogeomorfologia sertaneja identifica e cria taxonomia para aqueles processos e formas de relevo que têm influência mais direta sobre sua vida cotidiana. Por isso são classificadas duas formas básicas de relevo, baseadas na altimetria e nas declividades: as áreas altas e as áreas baixas. A primeira é relacionada às encostas, com declividades mais 
acentuadas e solos mais rasos, mais pedregosidade, onde o uso e o manejo procuram ser menos intensivos devido à ocorrência mais constante de processos de perda de material (erosões e movimentos gravitacionais de massa) - compreendidos e classificados por eles. As áreas baixas, lato sensu, referem-se àquelas rebaixadas e planas da paisagem, onde a umidade é mais constante, os solos apresentam maior profundidade e podem ser feitos usos e manejos menos restritivos que nas áreas altas, uma vez que o processo morfoesculturador mais comum é o de deposição de sedimentos, o qual é composto por material mais fino e rico em nutrientes, advindo das áreas altas.

Dentro dessa classificação geral há uma setorização da paisagem:

1 - As áreas altas subdividem-se em chapada, talhado, pé-de-serra, serra e serrote, individualizadas principalmente em relação às declividades e aos tipos de solo que apresentam.

2 - As áreas baixas subdividem-se em tabuleiros, areias e baixios, diferenciadas principalmente segundo o tipo de solo (arenoso ou argiloso) e o aporte de umidade, sendo os baixios também identificados pela quase ausência de declividades.

Assim, os conhecimentos etnogeomorfológicos identificados entre os diversos produtores rurais sertanejos de cultura de subsistência entrevistados nas terras da sub-bacia do rio Salgado/CE mostraram-se idênticos - tanto em relação aos conceitos sobre fertilidade, erosão, movimentos gravitacionais de massa e sedimentação quanto às denominações e tipos de classificação das formas de relevo.

A Etnogeomorfologia pretende contribuir, assim como as demais etnociências, para a construção de um novo modelo para a Geografia voltado ao desenvolvimento local, uma vez que configurações de conhecimento geomorfológico, classificação, interpretação e manejo das formas de relevo não são restritas ou originárias apenas do saber científico sistematizado. Como afirma Laraia (2009), a manipulação adequada e criativa do patrimônio cultural adquirido e acumulado através de gerações é o que dá suporte às inovações e às invenções.

\section{Agradecimentos}

Ao Conselho Nacional de Pesquisas (CNPq), pelo apoio financeiro na forma de bolsa de estudos de Doutorado. 


\section{Bibliografia}

AB’SABER, A. N. (1974) O domínio morfoclimático semiárido das caatingas brasileiras. Geomorfologia, $\mathrm{n}^{\circ} 43$.

AB'SABER, A. N. (2010) No domínio das caatingas. In MONDENESIGAUTIERRI, M. C.; BARTORELLI, A.; MANTESSO-NETO, V.; CARNEIRO, C. D. R.; LISBOA, M.B.A.L. (org.) A obra de Aziz Nacib Ab 'Saber. São Paulo: Beca-BALL edições. pp. 553-560.

ALVES, A. G. C.; MARQUES, G. W. (2005) Etnopedologia: uma nova disciplina? In: SBCS. Tópicos em Ciência do Solo, v. 4. Viçosa - MG: Sociedade Brasileira de Ciência do Solo. pp. 321-344.

BERTRAND, G.; BERTRAND, C. (2009) O sistema GTP (Geossistema, Territótio, Paisagem). O retorno do geográfico? In: BERTRAND, C.; BERTRAND, G. Uma geografia transversal e de travessias - o meio ambiente através dos territórios e das temporalidades. Maringá - PR: Massoni. pp. 305-306.

BOARDMAN, J. (1993) The sensitivity of downland arable land to erosion by water. In: THOMAS, D. S. G.; ALLISON, R.J. (org.) Landscape Sensitivity, Wiley, Chichester. pp. 211-228

BÓLOS I CAPDEVILA., M. de. (1981) Problemática actual de los estúdios de paisaje integrado. Revista de Geografia, v. 15, $\mathrm{n}^{\circ} 1-2$, enero-deciembre. Barcelona. pp. 45-68. Disponível em: http://www.raco.cat/index.php/RevistaGeografia/article/viewFile/45940/56 766. Acessado em: 17 set. 2010.

(org.). (1992) Manual de ciencia del paisaje: teoría, métodos y aplicaciones. Barcelona: Masson.

DAYRELL, C. A. (1998) Geraizeiros e biodiversidade no norte de Minas: a contribuição da agroecologia e da etnoecologia nos estudos dos agroecossistemas tradicionais. 182 f. Dissertação (Mestrado em Agroecologia) - Universidad Internacional de Andalucia, Sede Ibero Americana de La Rábida.

DIEGUES, A. C. S. (1996) O mito moderno da natureza intocada. São Paulo: HUCITEC.

ESCOBAR, A. (2005) O lugar da natureza e a natureza do lugar: globalização ou pós-desenvolvimento? In: LANDER, E. (org) $A$ colonialidade do saber: eurocentrismo e ciências sociais. Perspectivas latino-americanas. Ciudad Autônoma de Buenos Aires - AR: CLACSO (Colección Sur Sur). pp. 133-168. Disponível em: 
http://bibliotecavirtual.clacso.org.ar/ar/libros/lander/pt/Escobar.rtf. Acessado em: 10 jul. 2009.

FUNAI. PPTAL. (2004) Levantamentos Etnoecológicos em Terras Indígenas na Amazônia brasileira: uma metodologia Versão revista e atualizada. Brasília: FUNAI. Disponível em: http://www.funai.gov.br/pptal/download/LevantamentosEtnoecologicos.pd f. Acessado em: 5 jul. 2009.

LARAIA, R. B. (2009) Cultura: um conceito antropológico. 23.ed. Rio de Janeiro: Jorge Zahar Ed.

MATHEWSON, K.; SEEMANN, J. (2008) A geografia histórico-cultural da Escola de Berkeley: um precursor ao surgimento da História Ambiental. Varia Historia, vol. 24, no 39, jan/jun. Belo Horizonte. p.71-85.

RIBEIRO, S. C. (2012) Etnogeomorfologia sertaneja: proposta metodológica para a classificação das paisagens da sub-bacia do rio Salgado/CE. 278 f. Tese (Doutorado em Geografia) - Universidade Federal do Rio de Janeiro.

SAUER, C. O. (2007) Geografia cultural. In: CORREA, R.L.; ROSENDAHL, Z. Introdução à geografia cultural. Rio de Janeiro: Bertrand Brasil. pp. 19-26.

TRICART, J. (1977) Ecodinâmica. Rio de Janeiro: FIBGE.

. (1982) Paisagem e ecologia. Inter-Facies, escritos e documentos. São José do Rio Preto: Ed. da UNESP.

TUAN, Y. (1980) Topofilia: um estudo da percepção, atitudes e valores do meio ambiente. São Paulo: DIFEL.

- (1983) Espaço e Lugar: A perspectiva da Experiência.

Tradução de Lívia de Oliveira, São Paulo: DIFEL.

Data de submissão: 04/08/2014.

Data de aceite: 12/12/2014. 